\title{
Commentary: A Bird in the House: The Challenge of Being Ecologically Relevant in Captivity
}

\author{
Simon C. Griffith ${ }^{1 *}$, Ondi L. Crino ${ }^{2}$ and Samuel C. Andrew ${ }^{1}$ \\ ${ }^{1}$ Department of Biological Sciences, Macquarie University, Sydney, NSW, Australia, ${ }^{2}$ Centre for Integrative Ecology, School of \\ Life and Environmental Sciences, Deakin University, Geelong, VIC, Australia
}

Keywords: captivity, corticosterone, ethics, housing conditions, zebra finch

\section{A commentary on}

\section{A Bird in the House: The Challenge of Being Ecologically Relevant in Captivity by Beaulieu, M. (2016). Front. Ecol. Evol. 4:141. doi: 10.3389/fevo.2016.00141}

In his recent paper Beaulieu (2016) suggested that the conditions in which zebra finches are housed in research laboratories do not represent conditions in the wild, and may be stressful. These findings were based on his consideration of some Australian climate data and the levels of corticosterone reported in a range of published studies. We think there are problems with both Beaulieu's (2016) perspective on climate and day length, and his treatment and interpretation of corticosterone data from the literature, and we disagree with his main conclusion that laboratory climatic and day

OPEN ACCESS

Edited by: Geoffrey E. Hill,

Auburn University, USA

Reviewed by:

Douglas G. Barron,

Arkansas Tech University, USA Simon Verhulst,

University of Groningen, Netherlands

${ }^{*}$ Correspondence: Simon C. Griffith simon.griffith@mq.edu.au

Specialty section:

This article was submitted to Behavioral and Evolutionary Ecology,

a section of the journal

Frontiers in Ecology and Evolution

Received: 19 January 2017 Accepted: 15 March 2017 Published: 03 April 2017

Citation:

Griffith SC, Crino OL and Andrew SC (2017) Commentary: A Bird in the House: The Challenge of Being Ecologically Relevant in Captivity. Front. Ecol. Evol. 5:21. doi: 10.3389/fevo.2017.00021 length conditions are stressful for zebra finches.

Beaulieu (2016) found that the average conditions under which laboratory zebra finches are held is at a temperature of $22.2^{\circ} \mathrm{C}$, with a humidity of $45.8 \%$ and with $13.8 \mathrm{~h}$ a day of light, and concluded that zebra finches "are housed under conditions that would be perceived as a paradoxical season in the wild." We agree that these conditions are representative of typical conditions in captivity. In their recent review (Griffith et al., 2017), also collated temperature, humidity, and day length across a number of representative laboratory studies and found to be similar to those presented by Beaulieu (2016): average temperature $20.7^{\circ} \mathrm{C} \pm 2.1 S D$; humidity $48.9 \% \pm 15.0 S D$; day length $13 \mathrm{~h}$ 51 min (data from Table 1 in Griffith et al., 2017). As outlined below, we think that these laboratory conditions are representative of those experienced by wild zebra finches and that Beaulieu's (2016) representation of Australian climatic and photoperiodic conditions (and the interaction between them) is somewhat misleading.

The zebra finch is widely distributed across the desert and grassland biomes of Australia ( $>80 \%$ of the continent) and as such the species is exposed to extensive variation in climate and day length (temporally and spatially). Two populations of breeding zebra finch have been studied intensively in these biomes. Zann studied zebra finches in the grassland biome at Alice Springs, in central Australia, a location where they breed more erratically than elsewhere (Zann, 1996). By contrast, breeding is more reliable in the desert biome (Zann, 1996) and, for example, at Fowlers Gap in north-west New South Wales, they breed seasonally from August to December with a peak of breeding activity in October (Griffith et al., 2008). Therefore, Fowlers Gap provides an example of a site in the desert biome where zebra finches breed regularly and have been the focus of ongoing research since 2004 .

Over the period when clutches were laid between 2007 and 2010 at Fowlers Gap (Griffith et al., 2008; Mariette and Griffith, 2012) the mean daily temperature at the time of laying of 317 clutches of wild zebra finches was $19.42^{\circ} \mathrm{C} \pm 3.09 S D$ (Figure 1A), with a mean daily minimum of $12.44^{\circ} \mathrm{C} \pm 3.23 \mathrm{SD}$, and a mean daily maximum of $26.40^{\circ} \mathrm{C} \pm 3.09 \mathrm{SD}$ (all data sourced from Bureau of Meteorology as in 
Beaulieu, 2016). Therefore, in the wild, temperatures during breeding are variable, but overlap well with captive conditions. Similarly, humidity varies within and across days with climatic conditions and the amount of soil moisture (see Figure 1B for example). If we consider the daily variation in just October across the same years (month of peak breeding), the average humidity is $41.62 \% \pm 18.62 S D$ at 9 a.m.; and $23.29 \% \pm 15.53 S D$ at 3 p.m. The daily humidity levels ranged between 4 and $96 \%$ in the October of these exemplar years. Therefore, whilst the average conditions at 9 a.m. are slightly lower (41\% vs. $45-49 \%$ in laboratory), wild zebra finches are frequently exposed to a wide range of humidity conditions that are both higher and lower than those experienced in the laboratory. For both temperature and humidity, Beaulieu (2016) has presented and discussed the long-term average conditions, without considering that within and across days and months the actual conditions experienced are highly variable, and birds (and selection) are responding to actual conditions experienced rather than the long-term averages, which naturally appear to be relatively stable (e.g., Figure 1B).

In his consideration of day length, Beaulieu (2016) calculated the difference in time between sunrise and sunset, finding that a $14 \mathrm{~h}$ day only occurs at the summer solstice in the desert biome.
However, Beaulieu (2016) did not account for the period of light before and after the time of sunrise and sunset (civil dawn and dusk) the period of time that is defined as being light enough for normal human activity (and when the sun is within $6^{\circ}$ of the horizon). At Fowlers Gap, this adds over 50 min of daylight to the estimates calculated by Beaulieu (2016), and therefore during the key months of breeding the day lengths are actually: August $11 \mathrm{~h}$ $47 \mathrm{~min}$; September 12 h $42 \mathrm{~min}$; October 13 h $41 \mathrm{~min}$; November $14 \mathrm{~h} 39 \mathrm{~min}$. The period of day length that is typically used in the laboratory (around 13.5 Griffith et al., 2017; 13.8 h Beaulieu, 2016), matches well with the period of peak breeding (October) in the desert biome at Fowlers Gap, and across central Australia at a similar latitude.

Beaulieu (2016) concludes that standard housing conditions are a source of stress for zebra finches and presents data collated from 29 studies that show a negative association between housing temperature and baseline corticosterone levels. The term "stress" is often misleading and it is an oversimplification to conclude that elevated baseline levels of glucocorticoids indicate that an animal is in distress or has activated the "emergency life-history stage" (McEwen and Winfield, 2003; Romero, 2004). Glucocorticoids are steroid hormones that predominantly function to mobilize
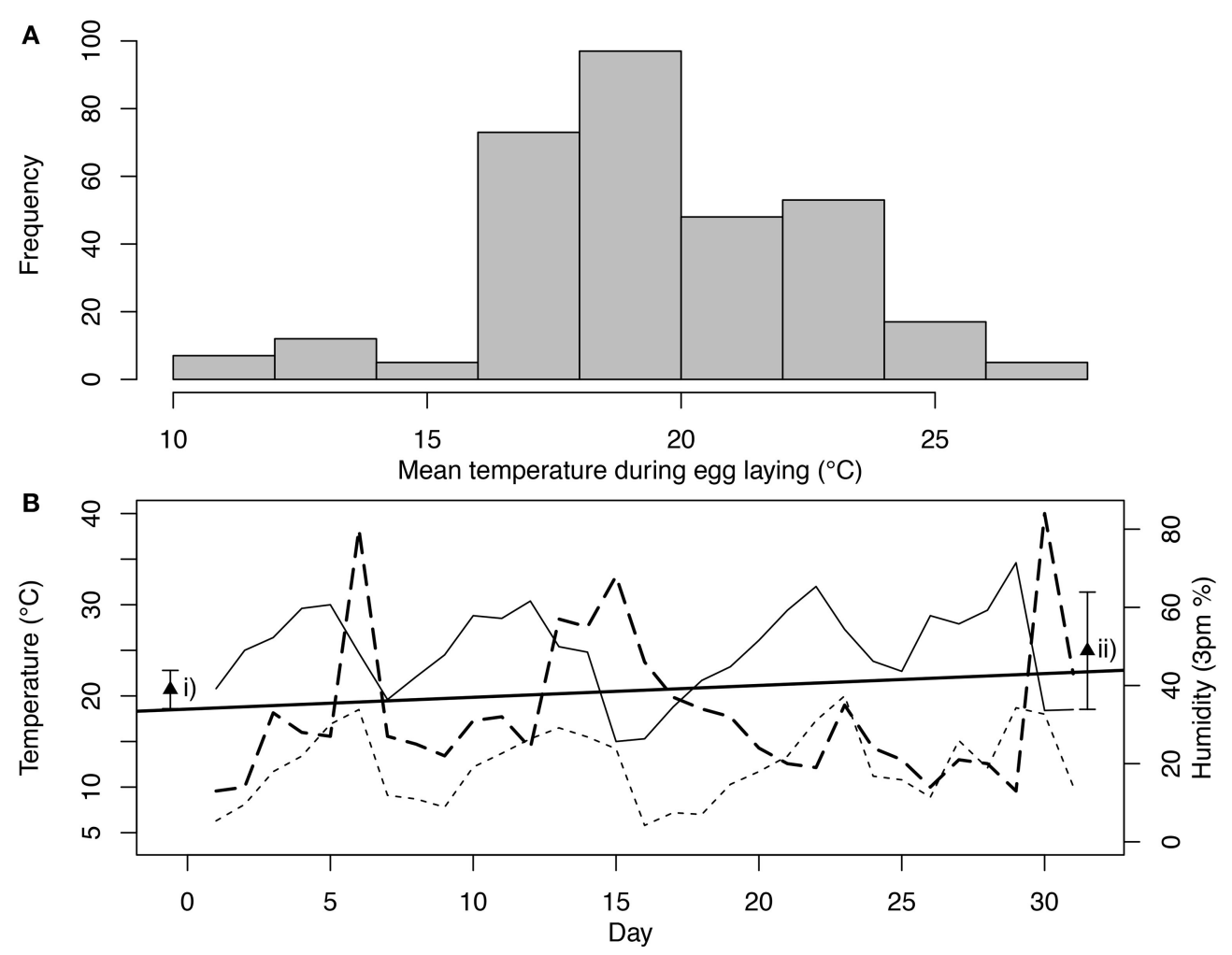

FIGURE 1 | Temperature conditions during Zebra finch breeding. Panel (A) is a frequency distribution of the mean average daily temperature during egg laying for 317 clutches that were observed at Fowlers Gap between 2007 and 2010 . The mean average daily temperature covers a period from 10 days before the first egg was laid until 5 days after the first egg date, when generally the last egg is laid. Panel (B) plots the temperature and humidity across the days of October in 2010. Maximum temperature is plotted as a solid line, minimum temperature is plotted as a dotted line and humidity at 3 p.m. is plotted as a long dashed line. The solid straight line is a line of best fit between the mean average temperature of September and November (on the $x$-axis the means are plotted in the middle of the month, 15 days before and after October). In panel b (i) plots the average temperature $( \pm S D$ ) in captive environments and (ii) plots the average humidity ( $\pm S D$ ) in captive environments (data from Griffith et al., 2017). 
stored energy and are continually secreted at low (baseline) levels (Dallman et al., 1994). Birds may experience changes in baseline corticosterone (the dominant avian glucocorticoid) levels at different life-history stages (e.g., reproduction: Pereyra and Wingfield, 2003) that are independent of a stress response. Therefore, comparing corticosterone levels across studies should be undertaken with care and factors that could affect levels such as reproductive state (Horton and Holberton, 2010), age (Heidinger et al., 2006), sex (Lormée et al., 2003), and condition (Crino et al., 2017) should be accounted for in statistical analyses.

Another challenge for comparative work, is that methods for assaying hormones vary between laboratories (e.g., enzymeimmunoassay vs. radioimmunoassay) and coefficients of variation for identical samples assayed at different labs can be as high as $70.4 \%$ (McMaster et al., 2001). Combining corticosterone data from across studies (as in Beaulieu, 2016) is likely to result in spurious conclusions in the absence of controls for differences between experimental assays, and the state of study animals (see above). There is also variation in how hormones values are reported. For example, in the supplemental material ("data sheet 1"), Beaulieu (2016) presents "basal" corticosterone data from across studies in terms of $\mathrm{ng} / \mathrm{ml}$, and includes a value of $93.5 \mathrm{mg} / \mathrm{ml}$ for the study by Krause and Ruploh (2016). However Krause and Ruploh (2016) standardized their data and their values were presented in a unit-less corticosterone index, i.e., they weren't actually values in $\mathrm{ng} / \mathrm{ml}$ as used by Beaulieu (2016) in his analysis. Future studies comparing hormone values across labs should be wary of this error. However, if sources of variation are adequately addressed and values interpreted correctly, the large number of studies that Beaulieu (2016) has identified, potentially open up exciting opportunities to answer sophisticated questions about stress physiology.

We conclude that average laboratory climatic and photoperiodic parameters are reflective of the conditions in which wild zebra finches live and breed (with the caveat that they are fixed rather than variable-see below), and that the evidence presented by Beaulieu (2016) that they are stressful is currently inconclusive. Future studies should standardize conditions in captivity as far as possible, and report them (see also Griffith et al., 2017), so that variation in those abiotic factors raised by Beaulieu (2016), are less likely to confound research findings in captivity. There are also good

\section{REFERENCES}

Beaulieu, M. (2016). A bird in the house: the challenge of being ecologically relevant in captivity. Front. Ecol. Evol. 4:141. doi: 10.3389/fevo.2016.00141

Briga, M., Koetsier, E., Boonekamp, J. J., Jimeno, B., and Verhulst, S. (2017). Food availability affects adult survival trajectories depending on early developmental conditions. Proc. R. Soc. B 284:20162287. doi: 10.1098/rspb.2016.2287

Briga, M., and Verhulst, S. (2015). Large diurnal temperature range increases bird sensitivity to climate change. Sci. Rep. 5:16600. doi: 10.1038/srep16600

Crino, O. L., Buchanan, K. L., Trompf, L., Mainwaring, M. C., and Griffith, S. C. (2017). Stress reactivity, condition, and foraging behavior in zebra finches: effects on boldness, exploration, and sociality. Gen. Comp. Endocrinol. 244, 101-107. doi: 10.1016/j.ygcen.2016.01.014 opportunities for further experimental manipulations to examine the physiological effects of light, temperature and humidity in captivity. Until such experimental work informs the optimal environmental conditions for this species in captivity, we suggest the average conditions we have reported above are a good starting point. We also note that a whole range of other environmental conditions such as housing, diet, social context, and the quality of light are also "unnatural" and their affects should be considered (reviewed in Griffith et al., 2017).

The other issue raised by a consideration of wild vs. captive conditions is that in captivity the conditions are stable rather than showing the variability found in the wild. The lack of variability - the controlled conditions of captivity-is one of the main reasons for conducting work on research animals in the laboratory. Controlling for the high level of variation in temperature, humidity and day-length that animals are exposed to in the wild, helps us to understand fundamental questions across the range of fields that have been addressed with the captive zebra finch (Griffith and Buchanan, 2010). We note also that the studies covered in Beaulieu's (2016) commentary demonstrated effects across sets of individuals held under the same conditions, and therefore the reported differences amongst the individuals in each study are still informative. Whilst holding captive animals under controlled conditions is an important rationale underlying captive animal work, there is merit in further attempts to examine the effect of fluctuating versus constant conditions (e.g., Briga and Verhulst, 2015), or to consider providing behavioral or physiological challenges that might challenge captive birds in a way that is similar to their wild counterparts (e.g., Briga et al., 2017). So in conclusion, whilst we disagree with many of Beaulieu's (2016) specific interpretations, we do agree that it is important to consider the effect of a range of environmental factors on physiology, behavior and reproduction in the captive zebra finch, as well as considering the ecological context in which it evolved (reviewed in Griffith et al., 2017).

\section{AUTHOR CONTRIBUTIONS}

SG and SA did the analysis of the data, SA put the figure together and all authors wrote the paper. 
Heidinger, B. J., Nisbet, I. C. T., and Ketterson, E. D. (2006). Older parents are less responsive to a stressor in a long-lived searbird: a mechanism for increased reproductive performance with age? Proc. R. Soc. B 273, 2227-2231. doi: $10.1098 / \mathrm{rspb} .2006 .3557$

Horton, B. M., and Holberton, R. L. (2010). Morph-specific variation in baseline corticosterone and the adrenocortical response in breeding white-throated sparrows (Zonotrichia albicollis). Auk 127, 540-548. doi: 10.1525/auk.2010.09096

Krause, E. T., and Ruploh, T. (2016). Captive domesticated zebra finches (Taeniopygia guttata) have increased plasma corticosterone concentrations in the absence of bathing water. Appl. Anim. Behav. Sci. 182, 80-85. doi: 10.1016/j.applanim.2016.06.003

Lormée, H., Jouventin, P., Trouve, C., and Chastel, O. (2003). Sex-specific patterns in baseline corticosterone and body condition changes in breeding red-footed boobies Sula sula. Ibis 145, 212-219. doi: 10.1046/j.1474-919X.2003.00106.x

Mariette, M. M., and Griffith, S. C. (2012). Conspecific attraction and nest site selection in a nomadic species, the zebra finch. Oikos 121, 823-834. doi: 10.1111/j.1600-0706.2011.20014.x

McEwen, B. S., and Winfield, J. C. (2003). The concept of allostasis in biology and biomedicine. Horm. Behav. 43, 2-15. doi: 10.1016/S0018-506X(02)00024-7

McMaster, M. E., Jardine, J. J., Ankley, G. T., Benson, W. H., Greeley, M. S. Jr., Gross, T. S., et al. (2001). An interlaboratory study on the use of steroid hormones in examining endocrine disruption. Environ. Toxicol. Chem. 20 2081-2087. doi: 10.1002/etc.5620200930

Pereyra, M. E., and Wingfield, J. C. (2003). Changes in plasma corticosterone and adrenocortical response to stress during the breeding cycle in high altitude flycatchers. Gen. Comp. Endocrinol. 130, 222-231. doi: 10.1016/S0016-6480(02)00568-3

Romero, L. M. (2004). Physiological stress in ecology: lessons from biomedical research. Trends Ecol. Evol. 19, 249-255. doi: 10.1016/j.tree.2004. 03.008

Zann, R. A., (1996). The Zebra Finch - A Synthesis of Field and Laboratory Studies. Oxford: Oxford University Press.

Conflict of Interest Statement: The authors declare that the research was conducted in the absence of any commercial or financial relationships that could be construed as a potential conflict of interest.

Copyright (c) 2017 Griffith, Crino and Andrew. This is an open-access article distributed under the terms of the Creative Commons Attribution License (CC BY). The use, distribution or reproduction in other forums is permitted, provided the original author(s) or licensor are credited and that the original publication in this journal is cited, in accordance with accepted academic practice. No use, distribution or reproduction is permitted which does not comply with these terms. 